\title{
A CLÍNICA GESTÁLTICA SOB A ÓTICA DO PSICOTERAPEUTA INICIANTE
}

The Gestaltic clínic under the beginner psychologist optic

La clínica gestáltica bajo la óptica del psicoterapeuta iniciante

\author{
Carlos Ming-Wau \\ Universidade de Fortaleza \\ Yadja do Nascimento Gonçalves \\ Márcia Duarte Medeiros \\ Centro Universitário Fanor Wyden \\ Deyseane Maria Araújo Lima \\ Faculdade Maurício de Nassau \\ Centro Universitário Christus
}

\begin{abstract}
RESUMO
A clínica gestáltica prioriza o vivido e o entrelaçamento da teoria e prática como componentes indissociáveis na constituição do setting psicoterapêutico. O objetivo desse artigo é discutir a clínica gestáltica do ponto de vista do psicoterapeuta iniciante, a partir de um caso clínico. Toma-se como ponto de partida as considerações do psicoterapeuta no uso da gestalt-terapia, atravessado pelo ciclo do contato e pela versão de sentido como referenciais teórico e vivencial que iluminaram sua propedêutica prática clínica. Os bloqueios do contato impossibilitavam a cliente de seguir o fluxo de sua vida e experienciar o aquiagora, impedindo o surgimento de awareness e o fechamento de situações inacabadas. Os fatores de cura foram percebidos quando a cliente passou a dar sentido às suas dores anímicas. A versão de sentido possibilitou o relato dos acontecimentos do encontro, na ênfase do vivido do psicoterapeuta, a fim de dar rumo ao divagar existencial da cliente.
\end{abstract}

Palavras-chave: Gestalt-Terapia; Versão de Sentido; Ciclo do Contato.

\begin{abstract}
The Gestaltic Clinic prioritize the experienced and the interlinking of the theory and practice as indissoluble componentes in the constitution of the psychologist setting. The objective of this article is to discuss the Gestaltic Clinic from the view point of the setting psychologist, from a clinic case. To take it as from start the consideration of the psychoterapist in the use of the gestalt-therapy across by the cycle of the contact and by the interpretation of the sense as theoric and living reference that illuminating its clinic practice therapeutic. The blockade of the contact made Teresa unable to follow the flow of her life and to take experience in the here-now, preventing the emergence of awareness and the closure of unfinished situations. The fator of cure perceived when Teresa passed to give importance to the sorrow od her soul. The interpretation of sense make possible the account of the happening of the meeting, in the emphasize of the living of the
\end{abstract}


psychologist, with the proposal of the give direction to the existencial to digress of Teresa.

Keywords: Gestalt-Therepy; Version of Sense; Cycle of Contact.

\section{RESUMEN}

La clínica gestáltica prioriza el vivido y el entrelazamiento de la teoría y práctica como componentes indisociables en la constitución del setting psicoterapéutico. El objetivo de este artículo es discutir la clínica gestáltica desde el punto de vista del psicoterapeuta principiante, a partir de un caso clínico. Se toma como punto de partida las consideraciones del psicoterapeuta en el uso de la gestalt-terapia, atravesado por el ciclo del contacto y por la versión de sentido como referenciales teórico y vivencial que iluminaron su propedéutica práctica clínica. Los bloqueos del contacto imposibilitaban a Teresa de seguir el flujo de su vida y experimentar el aquí-ahora, impidiendo el surgimiento de la conciencia y el cierre de situaciones inacabadas. Los factores de curación fueron percibidos cuando Teresa pasó a dar sentido a sus dolores anímicos. La versión de sentido posibilitó el relato de los acontecimientos del encuentro, en el énfasis del vivido del psicoterapeuta, con la propuesta de dar rumbo al divagar existencial de Teresa.

Palabras-clave: Terapia Gestalt; Versión de Sentido; Ciclo del Contacto.

\section{INTRODUÇÃO}

A clínica em Gestalt-terapia é constituída pelo entrelaçamento e pela indissociabilidade entre teoria e prática, consideradas nesse artigo, como pedras angulares para a formação do psicoterapeuta iniciante. A psicoterapia, nesse ponto de vista, tem como pressuposto ser um momento de arte, técnica e ciência, a fim de garantir que o processo de mudança seja consistente e tenha continuidade (Ribeiro, 2007). Sob essa perspectiva, a clínica psicoterápica é uma arte construída a cada encontro e seus fundamentos estão associados a diversos fatores, tais como: a relação de ajuda, o encontro entre psicoterapeuta e cliente, provocando tessituras que vão do caos à sinfonia harmoniosa de uma existência awareness ${ }^{1}$ consigo e com o mundo.

Nessa via do pensamento psicológico demarcado pela abordagem gestáltica como instrumento teórico, prático e vivencial para a psicoterapia, Perls (1975\1977b) afirma que as teorias são mapas que orientam o processo psicoterapêutico. Assim como os mapas nos orientam a chegarmos com mais facilidade a um determinado lugar, a teoria é revestida da expertise compreensiva para as vivências experimentadas no aqui-agora, que estão acontecendo no espaço entre as subjetividades presentes na psicoterapia. Para o criador da Gestalt-terapia, as concepções dualistas são predominantes em uma cultura epistemológica

\footnotetext{
${ }^{1}$ Esse conceito não dispõe de tradução em língua portuguesa. Ele está atrelado ao processo de conscientização, um dos pressupostos fundamentais da Gestalt-terapia.
} 
que prefere cindir a pessoa, como por exemplo, em corpo e mente, em contraposição a considera-lo como um organismo total.

A falsa dualidade entre teoria e prática se ancora na concepção da abordagem gestáltica que considera o organismo funcionando como um todo integrado (Machado \& Souza Filho, 2017). Com isso, frisa-se que nessa abordagem o homem é concebido como um organismo total e que as cisões não descrevem a totalidade humana, pelo contrário, os paradigmas dicotômicos são ameaças à humanidade (Perls, 1975\1977b). A partir das cisões, abrem-se diversas dificuldades para a compreensão do humano e suas vicissitudes, entre elas, algumas tendências a percebe-lo como separado da realidade em que habita. Portanto, teoria e prática são inextricavelmente interligadas, não sendo concebidas como dois campos separados, mas imbricados mutuamente.

Considerando-se a relevância da associação entre teoria e prática e verificando a óbvia falta de experiência e vivência dos diversos fundamentos fenomenológicos-existenciais, por parte dos psicólogos recém-formados cremos ser fundamental um olhar mais detalhado sobre esta problemática. Qual seja, a falta de prática do psicoterapeuta neófito que pode causar ou mesmo impedir o sucesso da psicoterapia em clínicas-escola. Nota-se, aqui, um problema importante que atravessa a formação de psicólogo: como fazer o uso adequado da teoria na prática clínica? Os campos teóricos e práticos são aclarados pelas vivências experimentadas no manejo clínico do psicoterapeuta iniciante, a partir de um caso clínico.

Sobre a indissociabilidade entre teoria e prática, é máster afirmar que há posicionamentos que preconizam haver incompatibilidade entre psicologia e política, teoria e prática, e ciência e ideologia. No entanto, acreditamos, juntamente com Perez, Meza, Rossoti e Bicalho (2010) que estes posicionamentos advêm de um padrão hegemônico de conhecimento. Assim, o estudo em gestalt-terapia, enquanto foco desse artigo, tende a ser permeado pelo investimento em capacitação teórica e experimentação vivencial das possibilidades emocionais do psicoterapeuta no encontro com seu cliente. Nesse aspecto, a busca do equilíbrio dialético entre essas polaridades visa formar psicoterapeutas comprometidos com as necessidades sociais e históricas, diante do contexto de imersão do saber psicológico e as nuances que se estabelecem com sua prática (Maia, Freire \& Oliveira, 2012).

Perls, Hefferline e Goodman (1951\1997, p.43) descrevem que o objeto de estudo da psicologia é "a operação da fronteira de contato no campo organismo/ambiente", posição influenciada pela Psicologia da Gestalt. Nesse sentido, as implicações que despontam do ofício de psicólogo, sobrepõem o setting clínico, considerando que o homem não vive em um mundo isolado, mas sua relação é perpassada pelas influências dos contextos social, histórico, cultural, econômico, religioso e político. Dessa forma, não há neutralidade no ato 
científico, pois ele está inserido na esfera dos sentidos que apontam para a compreensão do homem e suas relações (Amatuzzi, 2008).

O objetivo desse artigo é discutir a clínica gestáltica do ponto de vista do psicoterapeuta iniciante, a partir de um caso clínico, considerando teoria e prática como elementos pertinentes ao manejo psicoterápico. Toma-se como ponto de partida as considerações de um psicoterapeuta iniciante no uso da abordagem gestáltica e da versão de sentido como referenciais teórico e vivencial que iluminaram sua propedêutica prática clínica. Sob o ponto de vista da psicologia humanista, "o homem atual, presente, existente, é constituído pelas questões de sentido. Ora, a palavra é exatamente a questão de sentido" (Amatuzzi, 2008, p.11). A partir das concepções contemporâneas da Gestalt-terapia, o ciclo do contato de Ribeiro (2007) balizará as discussões do caso apresentado e apontará caminhos para as intervenções no setting psicoterápico.

\section{A PSICOTERAPIA COM BASE NA ABORDAGEM GESTÁLTICA}

A Gestalt-terapia surgiu de um movimento dissidente da psicanálise, compondo junto com algumas abordagens, entre elas, o Psicodrama e a Abordagem Centrada na Pessoa, a terceira força que é chamada de Psicologia Humanista. Ao tecer comentários sobre o Humanismo da Psicologia, Amatuzzi (2008) discorre que o Humanismo na Psicologia tem como ponto de partida, o atual, aquilo que se apresenta no aqui-agora. Assim, as bases epistemológicas da abordagem gestáltica enfatizam o vivido e a consciência, ao inebriar-se da Fenomenologia e do Existencialismo, correntes filosóficas que concebem o homem enquanto ser-no-mundo com responsabilidades, liberdade para escolha e múltiplas possibilidades de existência (Boris, Melo, \& Moreira, 2017).

A Gestalt-terapia se apropria das possibilidades de existência que são apresentadas no setting terapêutico e a pessoa é o único ser que tem a possibilidade de se ver no futuro e decidir os rumos de sua vida. A ênfase do trabalho em Gestalt-terapia está no vivido a partir da compreensão que prioriza a relação emergente no aqui-agora, adotando uma atitude pré-reflexiva (Ribeiro, 1999). O componente existencial da abordagem gestáltica concerne nas possibilidades infinitas de existência, num percurso de descobertas e redescobertas na vivência das oportunidades que surgem frente à vida (Yontef, 1998).

Sob a influência do movimento alemão da Psicologia da Gestalt, Perls (1969l1977a) considera que o organismo humano funciona como um todo, na promoção da integração no ambiente em que está inserido, autorregulando-se conforme as necessidades ambientais vão surgindo. O organismo não funciona independente do ambiente, pelo contrário, extrai do ambiente os subsídios necessários para a sua manutenção. O fundador da gestalt-terapia compreende que o organismo é um todo unificado, contrapondo-se às correntes psicológicas que cindem o homem em mente e corpo.

Rev. Nufen: Phenom. Interd. | Belém, 11(1), 22-38, jan. - abr., 2019. 
Ora, sendo o organismo considerado como um todo, sua imersão no ambiente é imprescindível para a sua sobrevivência, surgindo dessa relação a fronteirallimite de contato, no qual "todo ato contatante é um todo de awareness, resposta motora e sentimento - uma cooperação dos sistemas sensorial, muscular e vegetativo - e o contato se dá na superfíciefronteira no campo do organismo/ambiente" (Perls, Hefferline \& Goodman, 1951 11997, p.68). Dessa forma, a fronteira do contato tem como função a conexão entre organismo e o mundo ou o outro, operando na diferenciação entre o self e o outro (Yontef, 1998). O organismo e o meio formam uma totalidade que é compreendida como um campo que existe numa interdependência e é significado pela percepção do sujeito e do objeto, ambos num movimento de correlação mútua. O campo é considerado um espaço vital, o que implica na compreensão fenomenológica de espaço e não na percepção do espaço físico (Ribeiro, 1999).

O trabalho clínico em Gestalt-terapia está baseado na consideração do fenômeno como aquilo que se apresenta e é tomado como ponto de partida para o processo terapêutico, é a figura que emerge no fundo da vida do cliente, indo ao encontro da totalidade da existência (Almeida, 2010). Assim, na emergência do sofrimento psíquico que o cliente apresenta na clínica, o gestalt-terapeuta leva em consideração as diversas possibilidades que para ele estão obscuras, impedindo-o de perceber que em seu espaço vital há outras figuras que podem ser potencializadas na imensidão do fundo de sua existência.

O gestalt-terapeuta não tem como foco destrinchar a dor do seu cliente, pelo contrário, põe ênfase na liberdade do cliente para escolher seu destino, acreditando nos aspectos prazerosos da vida (Galli, 2009). O organismo saudável desempenha o processo fluido de formação e transformação de figuras (Carvalho \& Costa, 2010) com a expansão das possibilidades de existência e a ampliação do fundo vivencial. Nesse sentido, as possibilidades de dar rumo ao divagar não se esgotam, mas surgem a cada instante (Galli, 2009) no movimento constante de transformação e formação de figuras durante o trabalho psicoterapêutico.

A Gestalt-terapia preconiza a autorregulação organísmica, cunhada por Perls (1973\1988) como processo de homeostase. Quando o organismo não consegue realiza-lo e manter o seu equilíbrio no ambiente, ele está doente. Esse equilíbrio se dá através do contatofuga que o organismo desempenha. Durante a autorregulação organísmica, constata-se que as escolhas ocorrem de forma integradas e ratifica a proposta da gestalt-terapia enquanto abordagem psicológica que não cinde o homem em corpo e mente, mas integra pensamento e sentimento, e espontaneidade e deliberação (Yontef, 1998). Os conceitos saúde e a doença estão entrelaçados como polaridades complementares e ligados entre si, de forma imbricada, no viés qualitativo das relações do organismo. Assim, as psicopatologias e demandas clínicas 
não são consideradas de forma isolada, mas como aspectos que constituem a totalidade da pessoa na revelação dos ajustamentos criativos, a fim de preservar a saúde (Antony, 2009).

O ajustamento criativo funcional propicia ao organismo crescimento e desenvolvimento, na interação e relação entre pessoa e ambiente de forma nutritiva e com mudanças significativas nas experiências do organismo. Em oposição, acontece o ajustamento criativo disfuncional, no qual o organismo não consegue estabelecer contatos criativos no seu ambiente, ou ainda, esses contatos não the proporcionarão crescimento, ocorrendo a cristalização de comportamentos, impedindo o fluxo de fechamento de gestalten ${ }^{2}$ (Frazão, 2015). Atrelada aos conceitos de ajustamentos criativos funcional e disfuncional, está o conceito de fuga. Para Perls (1973\1988) a fuga não pode ser considerada enquanto boa ou má, no aspecto de adjetiva-la, mas considera-la com sentidos e significados que respondam às perguntas: como a fuga acontece na vida do cliente e quais os sentidos da fuga.

O organismo que se esquiva dos eventos desagradáveis que impedem o seu crescimento, está saudável, embora, quando a fuga acontece em demasia, esse organismo pode estar adoecido, acometido dos bloqueios do contato, a saber: fixação, dessensibilização, deflexão, introjeção, projeção, proflexão, retroflexão, egotismo e confluência. (Perls, 1969\1977a; Perls, 1973\1988; Ribeiro, 2007). Em contrapartida, a literatura da abordagem gestáltica (Antony \& Ribeiro, 2004, 2005; Ribeiro, 2007) apresenta os fatores de cura como polaridades contrárias para os bloqueios do contato, a saber: fluidez, sensação, consciência, mobilização, ação, interação, contato final, satisfação e retirada, alinhados aos bloqueios do contato, respectivamente. Os fatores de cura são concebidos como um processo de experienciação que a pessoa desenvolve e que possibilita a mudança (Ribeiro, 2007).

A fixação acontece quando o organismo estabelece fronteiras rígidas ou abertas em demasia, impossibilitando a entrada de elementos nutritivos e permitindo adentrar elementos tóxicos, respectivamente, ou ainda, quando o organismo se fixa no passado e focaliza mais energia do que no presente. A dessensibilização é uma ausência constante da definição dos sentimentos, no qual a pessoa não percebe os acontecimentos em sua volta, os sinais emitidos pelo corpo e embotamento afetivo. Assim, nesse bloqueio do contato, o organismo está inerte ao mundo Ihe rodeia (Carvalho \& Costa, 2010).

A deflexão se refere à evitação do contato com o ambiente e às outras pessoas. A introjeção é a internalização de crenças, valores e atitudes que são transmitidos pela família e pelo ambiente durante o crescimento e desenvolvimento da criança e que repercute na sua existência e interfere nas suas experiências futuras (Antony, 2009). Na introjeção ocorre a interrupção do contato que faz o organismo ingerir elementos tóxicos e não saudáveis para o

\footnotetext{
${ }^{2}$ Plural da palavra gestalt.
} 
seu desenvolvimento. No mecanismo neurótico da projeção, o organismo atribui ao meio e às outras pessoas as suas responsabilidades ou desejos (Perls, 1973\1988).

$\mathrm{Na}$ proflexão a pessoa busca compensar suas necessidades fazendo ao outro o que deseja que façam consigo, por vezes, essa tentativa de preenchimento das necessidades não encontra êxito (Antony \& Ribeiro, 2004). Na retroflexão é realizado o movimento oposto à proflexão, fazendo consigo o que deseja fazer ao outro ou aos objetos do ambiente, na liberação de energias contra o seu organismo, o que por vezes, pode ensejar destruí-lo (Perls, 1973|1988). O egotismo é caracterizado pela centralização em si mesmo e o organismo toma como foco as suas necessidades (Antony \& Ribeiro, 2004). E, quando o organismo está em confluência não há diferenciação entre si e o outro, entre as fronteiras e o espaço vital, enquanto empecilho de distinção das suas características idiossincráticas (Antony, 2009; Ribeiro, 2007).

Quanto aos fatores de cura, a fluidez é caracterizada pelo movimento, por atitudes de busca do novo, deixando fluir novos comportamentos e novas figuras. A sensação diz respeito a sentir-se integralmente como se é e a saída da frieza emocional, no acolhimento a novos estímulos e a atenção está voltada para os sinais emitidos pelo corpo. Enquanto isso, o fator de cura consciência acontece quando o organismo se dá conta de si de maneira clara e reflexiva, e está mais atento aos acontecimentos à sua volta, com percepções dos relacionamentos recíprocos entre as pessoas e as coisas. A mobilização diz respeito às mudanças e separação das necessidades do organismo e das necessidades dos outros, com a expressão dos sentimentos conforme são sentidos, sem receio das diferenças entre si e o outro (Ribeiro, 2007).

$\mathrm{Na}$ ação, o organismo expressa confiança nas outras pessoas, é responsável pelos seus atos, percebe como os seus problemas surgem e cria estratégias para finaliza-los. A interação é assentada na aproximação a outras pessoas e o contato firmado não exige recompensas, mas ajuda o organismo na interação com o outro e no seu reconhecimento como diferente e singular, com necessidades e anseios que lhe são característicos. No contato final a própria pessoa é a sua fonte de prazer e se relaciona com os pares de forma clara e direta. A satisfação é o processo pelo qual o organismo ver que a composição do mundo é feita pelas pessoas, que o outro é uma fonte de nutrição, prazer e crescimento. $A$ retirada acontece quando o organismo busca novos contatos no momento que considerar adequado, percebendo as diferenças entre si e o outro (Ribeiro, 2007).

O ciclo do contato foi o demarcador teórico utilizado para a compreensão do caso clínico e por meio de seus atravessamentos fenomenológicos e existenciais fomentou a discussão da forma de ser no mundo da cliente. As reflexões acerca da clínica na abordagem gestáltica sobrelevaram a incursão da teoria e da prática como elementos essenciais para a formação do psicoterapeuta iniciante. Assim, a proposta de discussão de novas possibilidades 
de (revi)ver a existência da cliente, floresceram no surgimento de awareness, que para Perls, Hefferline e Goodman (1951\1997, p.46) "a awareness não é uma reflexão sobre o problema, mas é ela própria uma integração criativa deste".

\section{O CICLO DO CONTATO A PARTIR DA EXISTÊNCIA DE TERESA}

Teresa, nome fictício da cliente, tinha 19 anos quando buscou atendimento psicoterápico numa Clínica-Escola de Psicologia, dizendo ser uma pessoa afetuosa e que gostava de ajudar as outras pessoas, principalmente amigos próximos e familiares. Foram realizados 19 atendimentos com a cliente, entre o período de maio e dezembro de 2016 . $\mathrm{Na}$ primeira sessão, Teresa foi convidada a assinar o Termo de Consentimento Livre e Esclarecido. A assinatura do termo faz parte do protocolo de atendimentos da clínica-escola, ratificando os preceitos éticos por parte do psicoterapeuta na relação com a cliente, principalmente quando se trata da publicação do material produzido em decorrência dos atendimentos, como estudo de caso, contanto que a identidade da cliente seja preservada. Assim, vale considerar que o sigilo e o anonimato da cliente envolvida foram mantidos, sendo utilizado codinome.

A resposta de Teresa à pergunta disparadora do primeiro atendimento, que versava sobre o motivo da sua busca por ajuda psicológica foi que precisava de alguém para conversar. Em seguida, desenvolveu uma demanda que tinha como ponto de embate os conflitos familiares e as percepções das suas novas experiências vivenciadas no momento da busca pelo atendimento - graduação em um curso na área da saúde, novos relacionamentos afetivos, namoro, divergências com a figura materna e seus irmãos, uma garota de 11 anos e um garoto de 8 anos.

A cliente afirmava nos atendimentos que as pessoas the procuravam para conversar e ela sempre as escutava, mas no momento que precisava de alguém para lhe escutar, não encontrava quem oferecesse a ela a atenção merecida. Seu pedido inicial soou como uma proflexão, pois escutava o outro com o intuito de ser escutada, ocasião na qual não tinha sucesso e ficava frustrada ao ser rejeitada. Sua vontade de ser escutada foi vivida várias vezes durante os atendimentos psicoterápicos realizados, com uma fala ininterrupta, rápida, lançando conteúdos que não eram esmiuçados por Teresa, mas suas palavras apresentavam o discurso de que não tinham a oportunidade de serem ditas no seio familiar e nos encontros com os amigos. O discurso apresentava os sentimentos de uma pessoa que ansiava ser aceita pelos pares, mostrar-lhes seu lugar de portadora da fala, e que oferece seus ouvidos para os outros e ao mesmo tempo deseja ser ouvida.

Nesse aspecto, a escuta e fala são ferramentas psicoterapêuticas importantes e proporcionam o movimento de awareness das experiências cotidianas no dia a dia (Almeida, 2010). O foco dos atendimentos foi o aqui-agora, tão caro à abordagem gestáltica, priorizando 
o organismo total de Teresa e as suas relações com ambiente e com os pares, que por ora Ihe ocasionava intenso sofrimento. Teresa foi convocada a diluir sua dor pela fala, e a atitude do psicoterapeuta iniciante foi além de escuta-la, perpassando a travessia dolorosa de sua vida, ressaltando suas responsabilidades frente às escolhas de sua vida. Ao dar voz à Teresa, os sentidos existenciais de suas experiências the proporcionaram crescimento e ressignificação de suas vivências dolorosas, que por um tempo, não tinham espaço para serem verbalizadas, como por exemplo, seu autodiagnóstico de depressão.

Em um dos atendimentos, Teresa refere autodiagnóstico de depressão, alegando ter vivido vários dias se sentindo triste. Sobre o autodiagnóstico, constatou-se uma evitação do contato com suas experiências de frustração de não conseguir ser ouvida pelos pares. Sob o ponto de vista de Teresa, o transtorno depressivo é a explicação mais adequada para a queixa proferida no setting terapêutico. Assim, a sua afirmação de ter iniciado um quadro depressivo foi a sustentação das suas vivências dolorosas e, ainda, decorrente ao autodiagnóstico, a angústia vivida foi minimizada pelos sintomas relatados (Dantas, Sá, \& Carreteiro, 2009). A descrição da depressão está associada ao seu comportamento de projetar nas pessoas o "deve ser" e introjetar "eu devo ser" ou "não devo ser". O humor deprimido de Teresa, mostrou-se associado à deflexão e ao egotismo, experienciado como uma fuga patológica dos contatos com o meio e a ausência de discriminação de contatos que poderiam promover o seu desenvolvimento.

A fixação na queixa sobre os conflitos em casa e por vezes o sentimento de incapacidade para resolver seus problemas foi um dos motivos que levou Teresa a procurar ajuda psicológica. Sentia-se parada no tempo e atribuía à dinâmica familiar o motivo de sua tristeza constante, autodiagnosticada como depressão. Um misto de fixação e dessensibilização confunde as ações de Teresa frente aos acontecimentos que vivia em casa, no seu círculo de amizade e nas relações com os colegas da faculdade. Afirmava o desejo de ir embora para uma ilha distante e não contatar ninguém, a fim de pensar rumos para sua vida, livre de qualquer compromisso com o próximo. A deflexão foi uma possibilidade de existência que Teresa perscrutou adotar no seu caminho, convém, assim, à luz de Perls (1973|1988), interrogar-se acerca dos motivos de sua fuga, e perceber os ajustamentos criativos adotados como formas de suportar as dores decorrentes dos conflitos em casa e com os pares.

No relato sobre a infância, Teresa exalta a relação com o seu pai e o idealiza como um herói, capaz de protege-la dos perigos do mundo, das intempéries da vida e suprir suas necessidades de carinho e atenção. O pai correspondia às suas expectativas e era o seu herói, mas a ação do tempo modificou sua percepção acerca dos comportamentos do seu genitor. Aos 11 anos, Teresa começou a ver diferenças na relação paterna, como algumas mudanças no comportamento: ausência do cuidado paterno para si, seus irmãos e agressões 
à mãe. A frustração tomou conta da sua vida e na adolescência cuidou dos irmãos enquanto a mãe trabalhava para manter a casa. $O$ cuidado dispensado aos irmãos fez Teresa afirmar que não viveu a fase da adolescência, considerando-se uma adulta jovem.

Descreveu-se como uma pessoa fria e que não ver razão para demonstrar as emoções, como sentir saudades de alguém, apresentando a dessensibilização, ratificada ao afirmar que as vezes ver a sua vida como uma telespectadora, sentindo-se deslocada da realidade de sua existência. Teresa adota a deflexão como uma estratégia para sobreviver no seu meio, esperando que as pessoas sintam a sua falta e evitando contata-las. No contato com os amigos, a relação com os pares está enfadonha, e por várias vezes muda de assunto ou a interação não é recíproca. Foge dos contatos por não se dar conta de suas necessidades. No seu processo psicoterápico, Teresa experimentava formas de contatar os pares, dessa vez, não relacionadas à proflexão, mas contatos nutritivos que fossem capazes de lhe proporcionar desenvolvimento.

Com a conturbação existencial experienciada, Teresa relatou duas vivências de comportamentos autodestrutivos: a primeira, aos 9 anos, com automutilação, mas interrompeu ao pensar no pai e na mãe. Para a cliente a automutilação aliviava o seu sofrimento, principalmente quando visualizava o sangue escorrer pelo seu punho, com cortes de pequena profundidade. Essa automutilação ratifica seu episódio depressivo relatado e apresentou seu comportamento de dessensibilização das emoções e retroflexão. Entre as crianças e adolescentes, a iminência de comportamentos autodestrutivos está associada a problemas com os familiares, nos relacionamentos intersubjetivos e na escola (Sousa et al., 2017). O cenário familiar de Teresa não Ihe garantia segurança para enfrentar os problemas da vida, e a opção encontrada para o alívio das dores subjetivas foi flagelar o próprio corpo, como forma de evacuar a tensão vivida em casa.

A segunda experiência autodestrutiva, aos 15 anos, foi através da ingestão de uma cartela de comprimidos com o objetivo de dormir e o episódio não foi comunicado aos pais. O sono é uma fuga de seus conflitos, e em alguns atendimentos sinalizou que tem vontade de ir para uma ilha deserta e dormir por um longo período de tempo. Entre o gênero feminino há maior incidência de tentativa de suicídio pela intoxicação exógena (Bahia, Avanci, Pinto, \& Minayo, 2017; Rosa, Oliveira, Arruda, \& Mathias, 2017) e a residência é o local de maior incidência para a ingestão dos medicamentos (Veloso et al., 2017).

Para a Gestalt-terapia, o comportamento suicida representa as dificuldades da pessoa em estabelecer uma relação entre figura e fundo. Assim, instala-se o caos, pois não há ligação entre figura e fundo, e surge a perca dos sentidos que revela a premente dificuldade para vivenciar situações de impotência frente às adversidades da vida (Fukumitsu \& Scavacini, 2013). Das tentativas de suicídio apresentadas por Teresa, a ambivalência estava predominante em seu discurso, pois anseia aplacar o seu sofrimento, e a via de escape para 
tal foi ingerir medicações e se automutilar, retrofletindo contra seu organismo o que ensejava fazer com o meio. Para evacuar o seu sofrimento anímico ligado à sua vontade de morte, foram realizados experimentos a fim de conectar os sentidos de sua vida com o aqui-agora, trazendo para a relação entre psicoterapeuta e cliente, questionamentos sobre os seus planos para o futuro e como Teresa anseia seguir sua jornada. Em alguns momentos, os seus planos para o futuro tinham relação com sua família, no primeiro instante, com a mãe, e em seguida com os seus irmãos.

A relação com a mãe tem uma inversão de papeis: a filha assume o lugar da mãe e a função de cuidadora da casa. Teresa se identifica com a figura materna e afirma que por vezes tem de ser mãe e ser filha, assim, há uma confluência entre esses papeis. Nessa relação houve a imposição de exigências para que a mãe assumisse a função de genitora e provedora do lar, abstenha-se de alguns comportamentos, como o uso de álcool, resolução de pendências financeiras, por exemplo, o que demonstra projetar na mãe os seus desejos de mudança. Nesse contexto, apresentou a sua concepção de família ideal que diverge da sua família atual. Para Teresa, na família perfeita os integrantes conversam entre si, e resolvem seus conflitos, espaço no qual reina a concordância, a paz e a harmonia, inume de discussões conflituosas e querelas, introjetando em seu cotidiano o modelo de família perfeita.

Em um dos atendimentos, Teresa descreveu um sonho: estava numa situação de perigo junto com o seu irmão e escutou a voz de um amigo, não identificando quem seria. A mãe chega e os protege, ao dizer para eles que não os abandonaria e os acompanharia por toda a vida. No sonho, a cliente se sentiu acolhida pela mãe, descrevendo-o como uma experiência agradável vivida naquele momento. Nesse sonho, Teresa expressou a necessidade de fechar a gestalt referente à ausência do cuidado materno. Os sonhos podem ser oportunidades para o fechamento de gestalten inacabadas e promovem a integração de conteúdos que foram alienados (Lima-Filho, 2015). Ao retornar ao estado de vigília, percebeu que o sonho é diferente da vida real e chorava quando fazia analogias às vivências de sua casa.

Após vários atendimentos, Teresa verbalizou em quantidade significativa a palavra eu. Ainda, discorre que está envolta em uma bolha, persistindo em atitudes de egotismo e que evita contatar as pessoas, principalmente pelo medo de ser magoada por elas. Relatou a dificuldade em dizer não, demonstrando-se conivente aos posicionamentos que os outros lançam a seu respeito. Ainda, Teresa não gosta de magoar as pessoas e por vezes esse sentimento é lançado para si, retrofletindo para o seu organismo o que poderia lançar ao outro. Dizer eu, foi o anúncio de seu processo de conscientização, quando passou a reconhecer suas necessidades e a ter como foco o seu equilíbrio organísmico, dando um salto qualitativo na resolução de suas gestalten. 
Teresa afirmou que não é a mãe dos seus irmãos, optando por mudar suas posturas, passando a cuidar de si. Nos atendimentos subsequentes, Teresa continua a expressar essa fala e se mostra apreensiva e preocupada quanto ao seu futuro, principalmente no desempenho da função materna, devido o cuidado aos seus irmãos. $A$ cliente faz uma analogia de sua vida como um quebra-cabeça, no qual falta uma peça que irá resolver todos os seus problemas. A peça que Ihe falta foi lançada, por ela, para o futuro, dizendo que tentará modificar os seus comportamentos e passará a viver melhor. No decurso do processo terapêutico, relatou que teve uma mudança significativa na relação com a mãe, passando a compartilharem momentos de descontração. Embora os conflitos tenham se reduzido, Teresa expressou em seu discurso que sente falta do cuidado materno.

Os fatores de cura perceptíveis no processo psicoterápico de Teresa foram mobilização, interação e retirada. Em um dos atendimentos, Teresa foi enfática ao dizer que não era mãe dos meus irmãos e que assumiria o seu lugar de filha, outorgando à sua mãe desempenhar o papel que antes ocupava, expresso, em um primeiro momento, no sonho relatado. Os conflitos familiares não cessarão de forma instantânea e abrupta, mas demandam um tempo para que a família encontre uma alternativa de aceitar as diferenças entre seus membros.

Teresa passou a interagir com as pessoas sem esperar que elas lhe retribuíssem os seus contatos e começou a verbalizar seus sentimentos, como reação ao que recebia do outro, emitindo seu ponto de vista e sem receio de se magoar frente às atitudes dos seus pares. Ainda, a cliente foi assertiva ao afirmar que iria cuidar de si, desenvolvendo estratégias de autocuidado, tais como, ouvir suas necessidades, parar para sentir seu corpo, por vezes, cansado, exigindo repouso. O sono se desloca de fuga para momento de descanso. Suas atribuições como estudante e filha exigiam posturas que extrapolavam seus papéis ao assumir as responsabilidades de outras pessoas.

Em algumas situações, Teresa ainda sente falta do cuidado materno, recorrente no seu discurso, mas ao dar voz ao seu sofrimento anímico, ao se escutar, aos poucos ela movimentou-se para compreender que seus medos, anseios, angústias, são de sua responsabilidade. Entra na baila a sabedoria organísmica, na qual Teresa estabelece uma hierarquia de necessidades para o fechamento de suas gestalten. Com isso, a finalização do processo psicoterapêutico se deu a partir do momento que Teresa percebeu que sua vida podia tomar o rumo que ela desejava, mudando seus passos no momento oportuno e enriquecendo-os de sentido conforme a suas escolhas e deliberações.

\section{A VERSÃO DE SENTIDO E OS APONTAMENTOS DO PSICOTERAPEUTA INICIANTE}


Durante os atendimentos de Teresa, foi utilizada a metodologia de base fenomenológica para a apreensão vivencial do que acontecia entre psicoterapeuta iniciante e a cliente. Apropriando-se do método da versão de sentido, após cada atendimento era redigido um texto sobre como aconteceu o encontro, do ponto de vista do psicoterapeuta. Esse material, enquanto produto do atendimento, era utilizado na supervisão e não correspondia à descrição da sessão anexada ao prontuário psicológico da cliente. A concepção de versão de sentido parte das considerações desenvolvidas por Amatuzzi (2008), que a define como uma relato escrito logo após o atendimento, com a finalidade de discorrer o acontecimento de forma livre e objetiva. A versão de sentido é considerada uma reação viva do encontro, assim, é tida como uma palavra primeira.

Estar diante de Teresa e presentificar seu divagar existencial e em seguida relatar os sentidos do encontro foi crucial no desenvolvimento de habilidades clínicas, aquém ao conhecimento teórico, adotando uma postura pré-reflexiva. A versão de sentido foi uma ferramenta potencializadora para a compreensão da existência de Teresa, principalmente no fato de permitir o entrelaçamento entre a teoria e a prática. As interlocuções da versão de sentido e do ciclo do contato na compreensão da existência de Teresa possibilitaram dar sentido ao encontro entre psicoterapeuta e cliente.

Revestido do referencial humanista, o importante do momento do encontro é a presença real do psicoterapeuta frente ao seu cliente, uma relação entre eu e tu, conforme a filosofia dialógica. Para Buber (1923|2001), a relação Eu-Tu se dá a partir do reconhecimento entre os atores da cena, nesse caso, do processo psicoterápico de Teresa, que expressou suas idiossincrasias quando passou a reconhecer o seu eu e a diferenciar suas necessidades das necessidades dos outros. Por outro lado, por conta da psicoterapia de Teresa ter acontecido em contexto de aprendizagem e aquisição de habilidades clínicas, o importante no processo formativo do psicoterapeuta iniciante é entrar em contato com os sentidos do encontro (Amatuzzi 2008), priorizando a relação entre eu e tu.

Assim, nos encontros com Teresa foi enaltecida essa relação e apropriando-se da atitude fenomenológica, a suspensão dos a prioris e postulações teóricas, que emergiram em momentos posteriores do processo formativo do psicoterapeuta iniciante. Nessa envergadura, esse método qualitativo de pesquisa, aponta caminhos para chegar a uma fala autêntica, a partir da atitude pré-reflexiva utilizada no momento da escuta e expressa, posteriormente, no relato escrito (Amatuzzi, 2008; Ribeiro, 1999, 2007). A pesquisa fenomenológica no âmbito da Psicologia tem 3 pilares: o processo de redução fenomenológica, a descrição do fenômeno e a especificação das experiências (Feijoo \& Mattar, 2014).

No processo de supervisão, as nuances do encontro foram atualizadas e se apresentavam como um relato vivido dos acontecimentos da sessão, tomando dimensões não percebidas em um primeiro momento, mas revividas no desenvolvimento do conteúdo que foi 
versado de sentido. A versão de sentido é um instrumento importante no trabalho de formação de psicoterapeutas iniciantes, pois o relato escrito, de forma pré-reflexiva, contém os anseios e sentimentos do psicoterapeuta diante do cliente atendido (Boris, 2008). Com a releitura das versões de sentidos novos sentidos são criados, surgem novos conteúdos que antes não foram percebidos (Amatuzzi, 2008). Com as leituras do conteúdo versado de sentido, o psicoterapeuta iniciante passa pelo processo de sofisticação de seu olhar clínico, apura seus sentidos e se abre às novas experiências com o seu cliente.

Desse modo, a psicoterapia de Teresa, com base na abordagem gestáltica, priorizou o encontro entre psicoterapeuta e cliente, e proporcionou o restabelecimento dos sentidos da vida, conforme ela vai se realizando no dia-a-dia (Ribeiro, 1999). A psicoterapia é um processo de mão dupla, e as tessituras construídas são decorrentes dos encontros e dos momentos experimentados nessa relação. O psicoterapeuta iniciante não está imune aos afetos decorrentes do encontro (Boris, 2008), pelo contrário, inebria-se desses afetos e num relato vivido dar voz aos seus sentimentos e anseios que surgem na apropriação do ofício de psicólogo.

\section{CONSIDERAÇÕES FINAIS}

À guisa de concluir esse artigo é importante fazer menção à indissociabilidade entre teoria e prática, ambas proponentes do processo psicoterápico e consideradas fundamentais para o manejo clínico na Abordagem Gestáltica. Para tanto, é imprescindível que o psicoterapeuta esteja awareness dos objetivos da psicoterapia e que seus processos homeostáticos estejam presentificados e conscientes. É máster ao psicoterapeuta realizar a homeostase, no que se refere à equilibração entre as necessidades do cliente, seus pressupostos teóricos, a técnica e os sentidos experimentados ao longo da psicoterapia. Desse modo, é imprescindível estar ciente de que a regulação organísmica entre a teoria e prática não é um acontecimento imutável no setting clínico. Em alguns momentos, uma delas há de se sobrelevar, permutando os rumos do processo psicoterápico.

Outrossim, considerar a diversidade do sofrimento anímico e suas vicissitudes em cada personalidade exige do psicoterapeuta fazer uso da atitude fenomenológica e compreender cada existência de forma singular e imbricada nos espaços vitais de inserção do organismo. O encontro entre Eu e Tu é fundamental para o manejo clínico, principalmente pelo fato da psicoterapia confrontar-se com subjetividades distintas, no qual um se propõe a ajudar aquele que the procura por não suportar as dores cotidianas. As escolhas acontecem no tempo do cliente que decide quando e como modificar seus comportamentos, uma vida projetada para o aqui-agora, para o real, com responsabilidades por suas escolhas e desejos.

Por fim, discutir a clínica gestáltica do ponto de vista do psicoterapeuta iniciante, a partir de um caso clínico, considerando teoria e prática como elementos pertinentes ao 
manejo psicoterápico, foi de relevância salutar para o psicoterapeuta iniciante. Os passos dados na aquisição de habilidades clínicas priorizaram o vivido, tomando como referência a amplitude das possibilidades de existência experimentadas no acompanhamento de Teresa. O seu caminhar toma um rumo, a sua existência é vivida como unânime, e há o reconhecimento do outro como parceiro de jornada, ou por vezes inimigo, propondo ao organismo contatar ou fugir dos elementos nutritivos ou tóxicos para o seu crescimento, respectivamente.

\section{REFERÊNCIAS}

Almeida, J. M. T. (2010). Reflexões sobre a prática clínica em Gestalt-terapia: possibilidades de acesso à experiência do cliente. Revista da Abordagem Gestáltica, 16(2), 217-221.

Amatuzzi, M. M. (2008). Por uma psicologia humana. 2a ed. Campinas, SP: Editora Alínea.

Antony, S. M. R. (2009). Os ajustamentos criativos da criança em sofrimento: uma compreensão da Gestalt-terapia sobre as principais psicopatologias da infância. Estudos e pesquisas em Psicologia, 9(2), 356-375.

Antony, S., \& RIBEIRO, J. P. (2004). A criança hiperativa: uma visão da abordagem gestáltica. Psicologia: Teoria e Pesquisa, 20(2), 127-134.

Antony, S., \& Ribeiro, J. P. (2005). Hiperatividade: doença ou essência um enfoque da Gestalt-terapia. Psicologia: Ciência e Profissão, 25(2), 186-197.

Bahia, C. A., Avanci, J. Q., Pinto, L. W., \& Minayo, M. C. S. (2017). Lesão autoprovocada em todos os ciclos da vida: perfil das vítimas em serviços de urgência e emergência de capitais do Brasil. Ciência \& Saúde Coletiva, 22(9), 2841-2850.

Boris, G. D. J. B. (2008). Versões de sentido: um instrumento fenomenológico-existencial para a supervisão de psicoterapeutas iniciantes. Psicologia Clínica, 20(1), 165-180.

Boris, G. D. J. B., Melo, A. K., \& Moreira, V. (2017). The influence of phenomenology and existentialism in gestalt-therapy. Estudos de Psicologia, 34(4), 476-486.

Buber, M. (2001). Eu e Tu (N. A. Von Zuben, Trad.). São Paulo: Centauro. (Obra original publicada em 1923).

Carvalho, L. C., \& Costa, I. I. (2010). A clínica gestáltica e os ajustamentos do tipo psicótico. Revista da Abordagem Gestáltica, 16(1), 12-18.

Dantas, J. B., Sá, R. N., \& Carreteiro, T. C. O. C. (2009). A patologização da angústia no mundo contemporâneo. Arquivos Brasileiros de Psicologia, 61(2), 1-9.

Feijoo, A. M. L. C., \& Mattar, C. M. (2014). A Fenomenologia como Método de Investigação nas Filosofias da Existência e na Psicologia. Psicologia: Teoria e Pesquisa, 30(4), 441447.

Fukumitsu, K. O., \& Scavacini, K. (2013). Suicídio e manejo psicoterapêutico em situações de crise: uma abordagem gestáltica. Revista da Abordagem Gestáltica, 19(2), 198-204. 
Frazão, L. M. (2015). Compreensão clínica em Gestalt-terapia: pensamento diagnóstico processual e ajustamentos criativos funcionais e disfuncionais. In.: L. M. Frazão, \& K. O. Fukumitsu (Orgs), A clínica, a relação psicoterapêutica e o manejo em Gestalt-terapia (pp. 83-102). São Paulo: Summus.

Galli, L. M. P. (2009). Um olhar fenomenológico sobre a questão da saúde e da doença: a cura do ponto de vista da Gestalt-terapia. Estudos e pesquisas em psicologia, 9(1), 5917.

Lima-Filho, A. P. (2015). Teoria e técnica do trabalho com os sonhos em Gestalt-terapia. In.: L. M. Frazão, \& K. O. Fukumitsu (Orgs), A clínica, a relação psicoterapêutica e o manejo em Gestalt-terapia (pp. 129-148). São Paulo: Summus.

Machado, I. M. I., \& Souza Filho, J. A. (2017). "Fritz Perls Husserliano?": um ponto de vista comparativo. Revista do Nufen, 9(3) 188-199.

Maia, J. V. M., Freire, J. C., \& Oliveira, M. A. (2012). "Versando sentidos" sobre o processo de aprendizagem em gestalt-terapia. Revista da Abordagem Gestáltica, 18(2), 179-187.

Perez, A. C., Meza, A. P., Rossotti, B. G. P. P., \& Bicalho, P. P. G. (2010). Da ética e da formação: cartografando práticas para além das normas. In.: C. E. Nórte \& A. L. L. F. Macieira (Orgs.), Formação: ética, política e subjetividades na psicologia (pp. 178-198). Rio de Janeiro: Conselho Regional de Psicologia.

Perls, F. S., Hefferline, R., \& Goodman, P. (1997). Gestalt-terapia. São Paulo: Summus. (Obra original publicada em 1951).

Perls, F. (1977a). Gestalt-terapia explicada. São Paulo: Summus. (Obra original publicada em 1969).

Perls, F. (1977b). Teoria e técnica de integração da personalidade. In.: J. O. Stevens, Isto é Gestalt (pp. 69-98). São Paulo: Summus. (Obra original publicada em 1975).

Perls, F. (1988). Abordagem Gestáltica e Testemunha ocular da Terapia. Rio de Janeiro: Guanabara Koogan. (Obra original publicada em 1973).

Ribeiro, J. P. (1999). Gestalt-terapia de curta duração. São Paulo: Summus.

Ribeiro, J. P. (2007). O ciclo do contato: temas básicos na abordagem gestáltica. São Paulo: Summus.

Rosa, N. M., Oliveira, R. R., Arruda, G. O., \& Mathias, T. A. F. (2017). Mortalidade por suicídio no Estado do Paraná segundo meios utilizados: uma análise epidemiológica. Jornal Brasileiro de Psiquiatria, 66(2), 73-82.

Sousa, G. S. S., Santos, M. S. P., Silva, A. T. P., Perrelli, J. G. A., \& Sougey, E. B. Revisão de literatura sobre suicídio na infância. (2017). Ciência \& Saúde Coletiva, 22(9), 30993110

Veloso, C., Monteiro, C. F. S., Veloso, L. U. P., Figueiredo, M. L. F., Fonseca, R. S. B., Araújo, T. M. E., \& Machado, R. S. (2017). Violência autoinfligida por intoxicação exógena em um serviço de urgência e emergência. Revista Gaúcha de Enfermagem, 38(2), e66187. 
Yontef, G. M. (1998). Processo, Diálogo e Awareness: ensaios em Gestalt-terapia. São Paulo: Summus.

\section{NOTA SOBRE OS(AS) AUTORES(AS):}

Carlos Ming-Wau - Psicólogo. Mestrando em Psicologia pela Universidade de Fortaleza - UNIFOR. Bolsista da Fundação Cearense de Apoio ao Desenvolvimento Científico e Tecnológico - FUNCAP. E-mail: carlosmingwau@yahoo.com.br.

Yadja do Nascimento Gonçalves - Psicóloga, docente do curso de graduação em Psicologia do Centro Universitário Fanor Wyden - UNIFANOR WYDEN. Mestre em Saúde da Criança e do Adolescente. E-mail: yadjang@gmail.com.

Deyseane Maria Araújo Lima - Psicóloga Clínica. Doutora em Educação. Mestre em Psicologia. Especialista em Psicologia Clínica (Conselho Federal de Psicologia). E-mail: deyseanelima@yahoo.com.br.

Márcia Duarte Medeiros - Possui graduação em Processamento de Dados e em Psicologia. Mestrado em Psicologia pela Universidade Federal do Ceará e Doutorado em Educação Brasileira. E-mail: marciaduarte@msn.com.

\section{Agradecimentos}

O primeiro autor agradece à Fundação Cearense de Apoio ao Desenvolvimento Científico e Tecnológico - FUNCAP, pela bolsa de mestrado, em curso, na Universidade de Fortaleza.

Recebido: $11 / 06 / 2018$.

Aprovado: 14/03/2019. 